Research Article

\title{
Comprehensive Evaluation of Talent Growth Factor Index System Based on Hesitant Fuzzy Language
}

\author{
Xueer Ji $\mathbb{D},{ }^{1}$ Lei Wang $\mathbb{D}^{2},{ }^{2}$ and Huifeng Xue $\mathbb{D}^{1}$ \\ ${ }^{1}$ China Aerospace Academy of Systems Science and Engineering, Beijing 100035, China \\ ${ }^{2}$ School of Economics and Management, Xi'an University of Posts and Telecommunications, Xi'an 710065, China \\ Correspondence should be addressed to Xueer Ji; jixueer@mail.nwpu.edu.cn
}

Received 5 March 2021; Revised 15 June 2021; Accepted 16 August 2021; Published 26 November 2021

Academic Editor: Efthymios G. Tsionas

Copyright (C) 2021 Xueer Ji et al. This is an open access article distributed under the Creative Commons Attribution License, which permits unrestricted use, distribution, and reproduction in any medium, provided the original work is properly cited.

An effective evaluation of the index system of talent growth factors can lay a solid foundation to build the talent pool, as well as select and establish talents. In this study, based on the theory of "Man-Machine-Environment" system engineering (MMESE), the MMESE talent growth factor index system is proposed and verified for its effectiveness by comparing it with the traditional system. Based on the text-free grammar and transformation function, expert judgments of talent growth factor indexes were transformed into hesitation fuzzy language terms, namely, pertinence, systematicness, practicability, foresight, and dynamics, which were then used to create a dataset to describe the comprehensive evaluation of the index system. The entropy of hesitation fuzzy language terms adopts the algorithm, which calculates the index weights according to the relative entropy values and adjusts the expert weights with the expert group consensus model. The expert evaluation information was weighed and transformed into the corresponding probability language combination which was calculated as the comprehensive evaluation result of the talent growth factor index system.

\section{Introduction}

In the 21st century, the talent shortage is one of the main bottlenecks in human resource development across the world, which would affect global, economic, and social growth. In addition to the unbalanced growth of economic development, the main reason for the global talent shortage is the lack of scientific and effective talent evaluation methods and a reasonable talent training model. Therefore, it is of great significance for the global talent training strategic plans to carry out research on the index system of talent growth factors and build a scientific and effective comprehensive evaluation index system for talents.

Scholars have made extensive investigations about the establishment of index systems and comprehensive evaluation methods for talent growth factors. Qiu [1] studied the construction of the evaluation system of international applied talents from both qualitative and quantitative aspects, trying to solve the student evaluation problem in colleges and universities under the background of internationalization and provide a reference for the talent selection. Tian et al. [2] studied the internal and external influencing factors that affect the connotation, characteristics, and growth rules of innovative talents and revealed that external environmental factors, including physiological, psychological, and intellectual ones, are involved. Liu [3] classified the factors affecting the growth of innovative talents into four categories, namely, personal quality, education, working environment, social system, and innovative culture. The study demonstrated that the current management system is insufficient to cultivate scientific and technological talents in China. In addition, Labib et al. [4] suggested that the employee selection process uses AHP, and it requires four steps. Petrovic-Lazarevic [5] proposed a fuzzy model of two-level employee selection to minimize the subjective judgments of appropriate and inappropriate employees in the workplace. Due to the uncertainty of the boundaries of talent evaluation indicators, fuzzy comprehensive evaluation is widely used. However, fuzzy evaluation only uses the degree of a single language term to characterize 
the value of language variables, and it sometimes does not accurately reflect the true opinions of experts. For this reason, Rodriguez et al. [6] proposed the concept of hesitant fuzzy linguistic term set (HFLTS), which uses text-free grammar and transformation functions to transform the expert's decision language into an operable hesitant fuzzy language set. After the hesitation fuzzy language set was proposed, many scholars proposed different decisionmaking methods based on HFLTS for the qualitative decision-making problem given by expert decision information in the form of linguistic expressions, such as hesitation fuzzy language TODIM method [7], hesitation fuzzy language consensus model of group decision-making [8], and hesitant Pythagorean fuzzy ELECTRE-II method for multicriteria decision-making problems [9].

Despite all previous efforts, they are insufficient in several aspects. Firstly, previous studies that analyze talent growth factors with traditional methods have failed to reach the current standard, and they were simply based on a simple systematic analysis of the individuals and the external environment. Besides, research studies on talent growth factor indexes based on MMESE remain unavailable till now. Secondly, even though the comprehensive evaluation methods have made quantitative analyses on the index systems, most research methods are dependent on data accuracy and the completeness of the index system, making them less competitive compared with the index system evaluation white expert scoring. To address these insufficient aspects, this paper adopts the hesitation fuzzy language decision-making method to solve the problem of experts' languages in talent evaluations.

In response to the abovementioned research deficiencies, this study comprehensively analyzes the internal and external factors affecting the growth of talents from the perspective of "human-machine-environment" systems' engineering and constructs an indicator system for MMESE talent growth factors. In the comprehensive evaluation method of the index system, based on the text-free grammar and conversion function, the expert's judgment language on the talent growth factor index is converted into hesitant fuzzy language terms, and the hesitant fuzzy language term set is used to express the single characteristic evaluation information of the index system, that is, pertinence, systematic, complete, practical, forward-looking, and dynamic. On this basis, the expert group consensus model is used to further adjust the weight of experts, and the evaluation information given by the experts is weighted and integrated and transformed into the corresponding probabilistic language combination, and the expected value of the probabilistic language combination is calculated as the comprehensive evaluation result of the talent growth factor index system, so as to realize the qualitative comprehensive evaluation of the index system.

\section{Establishment of MMESE Talent Growth Factor Index System}

In 1981, under the guidance of the famous scientist Academician Qian Xuesen, a comprehensive marginal technology science-Man-Machine-Environment System Engineering came into being [10]. The interaction of man, machine, and environment is not a simple cycle, but follows a spiral development process. On the one hand, MMESE studies the performance of human, machine, and environment; on the other hand, it attaches importance to the coupling relationship among the three elements and their coordination methods. MMESE's research content mainly includes seven aspects (Figure 1): (1) research on human characteristics, (2) research on the machine characteristics, (3) research on environment characteristics, (4) research on the relationship between human and machine, (5) research on the relationship between human and environment, (6) research on the relationship between machine and environment, and (7) research on the overall performance of man-machine-environment system [11].

MMESE engineering theory is an important foundation to establish talent growth factor indexes. Nowadays, as science and technology continue to advance, almost all cutting-edge scientific researches and technical works are controlled by computers. As a result, the growth rate of talents is significantly higher, and the traditional structure of the index system of talent growth factors is subject to great changes. Electronic computers have changed the role of human beings from direct operators to decision makers, expanding and partially replacing the function of human mental work. Consequently, human beings devote themselves to intelligent activities at higher levels [12].

According to [13-16], personal ability, physical and mental health, moral quality, family environment, social environment, and innovation capability are the most frequently mentioned influencing factors. Based on the MMESE theory, we divide the index system into three parts, namely, human, machine, and environment. Specifically, "human" factors are health level, personal capability, and moral quality and "machine" factors are levels of information education and infrastructure, as well as the construction of a decision support system. Finally, "environment" factors are divided into macro and micro ones, where the former includes the environment of economy, policy, culture, science and technology, and education, and the latter includes the environment of family, work, and personal education (Table 1).

The talent growth factor evaluation system based on MMESE reflects not only the advanced stage of human intellectual development but also impacts of machines and the external environment on talent growth. Human beings and computers have their own respective pros and cons. For example, computers are more efficient when performing tremendous amounts of repetitive and programmed work, while human beings are more advantageous in completing advanced and creative thinking tasks.

\section{Comprehensive Evaluation Model of Talent Growth Factor Index System}

The comprehensive evaluation of a talent growth factor index system is a highly complex and uncertain decisionmaking problem, which is difficult for quantitative 


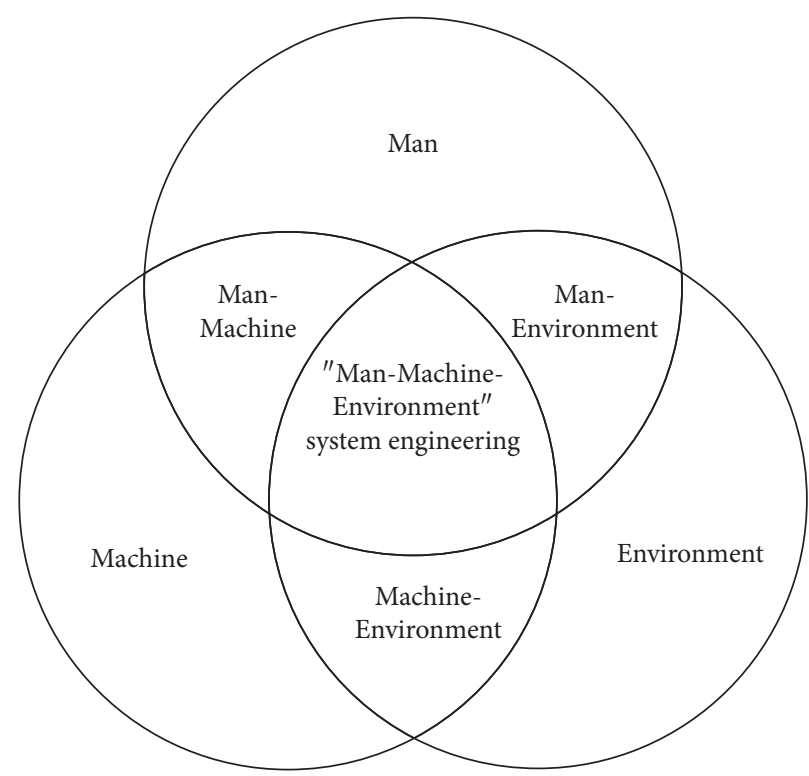

FIGURE 1: Schematic diagram of the relationship among human, machine, and environment.

TABLE 1: MMESE talent growth factor index system.

\begin{tabular}{|c|c|c|c|c|c|c|}
\hline Target layer & Subtarget layer & & & Index layer & & \\
\hline \multirow{9}{*}{$\begin{array}{l}\text { MMESE talent } \\
\text { growth factor } \\
\text { index system }\end{array}$} & \multirow{3}{*}{ Men } & Level of health & $\begin{array}{l}\text { Physiological } \\
\text { factors }\end{array}$ & $\begin{array}{l}\text { Psychological } \\
\text { factor }\end{array}$ & Health awareness & \multirow{6}{*}{$\begin{array}{c}\text { Information } \\
\text { security } \\
\text { technology }\end{array}$} \\
\hline & & Personal ability & Knowledge level & Core competence & Cognitive ability & \\
\hline & & Moral character & $\begin{array}{c}\text { Social } \\
\text { responsibility }\end{array}$ & Dedication & Integrity level & \\
\hline & \multirow{3}{*}{ Machine } & $\begin{array}{l}\text { Information } \\
\text { education }\end{array}$ & $\begin{array}{l}\text { Digital } \\
\text { education } \\
\text { resources }\end{array}$ & $\begin{array}{c}\text { Mathematics and } \\
\text { application }\end{array}$ & Education guarantee & \\
\hline & & $\begin{array}{l}\text { Information } \\
\text { infrastructure }\end{array}$ & $\begin{array}{l}\text { Computer } \\
\text { technology }\end{array}$ & $\begin{array}{l}\text { Network } \\
\text { technique }\end{array}$ & $\begin{array}{l}\text { Communication } \\
\text { technology }\end{array}$ & \\
\hline & & $\begin{array}{l}\text { Decision support } \\
\text { system }\end{array}$ & Database & Knowledge base & Simulation library & \\
\hline & \multirow{3}{*}{ Environmental } & Macroenvironment & $\begin{array}{c}\text { Economic } \\
\text { environment }\end{array}$ & $\begin{array}{c}\text { Policy } \\
\text { environment }\end{array}$ & $\begin{array}{c}\text { Cultural } \\
\text { environment }\end{array}$ & \multirow[t]{3}{*}{$\begin{array}{l}\text { Science and } \\
\text { technology } \\
\text { environmen }\end{array}$} \\
\hline & & & $\begin{array}{l}\text { Educational } \\
\text { environment }\end{array}$ & & & \\
\hline & & Microenvironment & $\begin{array}{c}\text { Family } \\
\text { environment }\end{array}$ & $\begin{array}{c}\text { Work } \\
\text { environment }\end{array}$ & $\begin{array}{c}\text { Personal education } \\
\text { environment }\end{array}$ & \\
\hline
\end{tabular}

evaluations. Therefore, it is necessary to build a reasonable and simplified model to address such problems. Torra [17] put forward the concept of hesitation fuzzy sets that describes decision attributes whit a set of multiple evaluation results. In addition, since language information is closely related to the experts' expression habits, hesitations may occur when using language to express 09 evaluation results. For example, Rodriguez et al. [18] proposed the concept of a hesitation fuzzy language term set, which allows experts to use multiple continuous language terms to express their evaluations. Compared with the traditional quantitative evaluation method, the hesitation fuzzy language decisionmaking method has good applicability when dealing with complex decision-making problems. In addition, the field has made deep investigations about group decision-making based on the hesitation fuzzy language term set. In this paper, information about express evaluations is adopted as a component of the comprehensive evaluation information, and the hesitation fuzzy information entropy is used to calculate the weights of evaluation attributes. Moreover, a consensus model is built to integrate expert evaluation opinions. With this consensus model, both the traditional and MMESE talent growth factor index systems can be evaluated accurately and comprehensively.

Based on the risk assessment model of hesitation fuzzy languages, the experts' evaluation languages were transformed into hesitation fuzzy language terms with the textfree grammar and transformation function. The matrix of 
the hesitation fuzzy language term set was used to describe the experts' comprehensive evaluation information on the talent growth factors index system, and the weights of evaluation attributes were calculated based on the matrix. Subsequently, the weights of experts were adjusted by the consensus model to create a group consensus across the expert evaluation opinions. Finally, the expert evaluation information was weighted and integrated to obtain the comprehensive evaluation result of the talent growth factor index system (Figure 2).

\subsection{Hesitation Fuzzy Language Term Set}

Definition 1 (see [19]). If there is a linguistic term set $S=\left\{s_{g} \mid g=-\tau, \ldots,-1,0,1, \ldots, \tau\right\}$, then a continuous and ordered finite subset $H_{S}=\left\{\left\{s_{i}, s_{i+1}, \ldots, s_{j}\right\} \mid s_{k} \in S, k=i, i+\right.$ $1, \ldots, j\}$ is a hesitant fuzzy linguistic term set. Specifically, $S$ is a language term set with an odd number of language variables. The subscripts of elements in $S$ take 0 as the symmetry center, and $s_{-\tau}$ and $s_{\tau}$ are the lower and upper bounds of language variables. $\tau$ is a positive integer. The elements in $S$ satisfy the following conditions:

(1) Ordering: if $\alpha>\beta$, there is $s_{\alpha}>s_{\beta}$

(2) Existence of negative operator: $\operatorname{neg}\left(s_{\alpha}\right)=s_{-\alpha}$, where $\operatorname{neg}\left(s_{0}\right)=s_{0}$

In addition, in order to maintain the given language information as much as possible during calculation, a continuous language term set [19] was proposed as $\bar{S}=\left\{s_{\alpha} \mid \alpha \in[-q, \underline{q}]\right\}$, where $q(q>\tau)$ is a sufficiently large positive integer. $\bar{S}$ is called the virtual language term set that is only used in calculations, while $S$ is still used in the expert decision-making.

For any two language terms $s_{\alpha}, s_{\beta} \in \bar{S}$ and $\lambda, \lambda_{1}, \lambda_{2} \in[0,1]$ in $\bar{S}$; the calculation must follow the following rules:

$$
\begin{aligned}
& s_{\alpha} \oplus s_{\beta}=s_{\alpha+\beta} \\
& \text { (1) } \lambda s_{\alpha}=s_{\lambda \alpha} \\
& \text { (2) }\left(\lambda_{1}+\lambda_{2}\right) s_{\alpha}=\lambda_{1} s_{\alpha} \oplus \lambda_{2} s_{\alpha} \\
& \text { (3) } \lambda\left(s_{\alpha} \oplus s_{\beta}\right)=\lambda s_{\alpha} \oplus \lambda s_{\beta}
\end{aligned}
$$

For the hesitation fuzzy language term set $H_{S}, H_{S}^{1}$, and $H_{S}^{2}$ on the language term set $S$, its algorithm is defined as follows [20]:

(1) $H_{S}^{1}$ and $H_{S}^{2}$ take the larger operator as $H_{S}^{1} \vee H_{S}^{2}=\left\{\max \left\{s_{i}, s_{j}\right\} \mid s_{i} \in H_{S}^{1}, s_{j} \in H_{S}^{2}\right\}$

(2) $H_{S}^{1}$ and $H_{S}^{2}$ take the smaller operator as $H_{S}^{1} \wedge H_{S}^{2}=\left\{\min \left\{s_{i}, s_{j}\right\} \mid s_{i} \in H_{S}^{1}, s_{j} \in H_{S}^{2}\right\}$

(3) The upper bound $H_{S}^{+}$and lower bound $H_{S}^{+}$of $H_{S}$ are $H_{S}^{+}=\max \left\{s_{i} \mid s_{i} \in H_{S}\right\}$ and $H_{S}^{-}=\min \left\{s_{i} \mid s_{i} \in H_{S}\right\}$

(4) The envelope set of $H_{S}$ is $\operatorname{env}\left(H_{S}\right)=\left[H_{S}^{-}, H_{S}^{+}\right]$

Definition 2 (see [19]). Let $S$ be a language term set and $G_{H}$ be a text-free grammar; then, $G_{H}=\left(V_{N}, V_{T}, I, P\right)$, where $V_{N}=\{$ subject, compound word, unary relation, binary relation, conjunction $\}, V_{T}=$ "less than," "more than," "at least," "at most," "between," “and," “s $s_{-\tau}$ ", . ., " $s_{0}$, " ..," " $s_{\tau}$ ”, and $\mathrm{I} \in V_{\mathrm{N}} ; P=\{\mathrm{I}$ refers to a subject or compound; The subject refers to " $s_{-\tau}$," ..., " $s_{0}$ ", ..., " $s_{\tau}$ "; Compound words refer to unary relation + subject, or binary relation + conjunction + subject; Unary relation refers to "less than" or "more than"; Binary relation refers to "between..."; Conjunctions refer to "and"\}.

Definition 3 (see [19]). Assuming that function $E_{G_{H}}$ can convert the language expression $l l \in S_{l l}$ generated by $G_{H}$ into the hesitation fuzzy language term set $H_{S}, S$ is the language term set adopted by $G_{H}$, and $S_{l l}$ is the set of all expressions generated by $G_{H}$. Then, the language expression generated by $G_{H}$ can be converted into $H_{S}$ by the transformation function $E_{G_{H}}: S_{l l} \longrightarrow H_{S}$ :

(1) $E_{G_{H}}\left(s_{t}\right)=\left\{s_{t} \mid s_{t} \in S\right\}$

(2) $E_{G_{H}}$ (at most $\left.s_{\alpha}\right)=\left\{s_{t} \mid s_{t} \in S\right.$ and $\left.s_{t} \leq s_{\alpha}\right\}$

(3) $E_{G_{H}}$ (less than $s_{\alpha}$ ) $=\left\{s_{t} \mid s_{t} \in S\right.$ and $\left.s_{t}<s_{\alpha}\right\}$

(4) $E_{G_{H}}$ (at least $s_{\alpha}$ ) $=\left\{s_{t} \mid s_{t} \in S\right.$ and $\left.s_{t} \geq s_{\alpha}\right\}$

(5) $E_{G_{H}}$ (larger than $\left.s_{\alpha}\right)=\left\{s_{t} \mid s_{t} \in S\right.$ and $\left.s_{t}>s_{\alpha}\right\}$

(6) $E_{G_{H}}$ (between $s_{\alpha}$ and $s_{\beta}$ ) $=\left\{s_{t} \mid s_{t} \in S\right.$ and $\left.s_{\alpha} \leq s_{t} \leq s_{\beta}\right\}$

3.2. Hesitation Fuzzy Language Entropy. Let the hesitation fuzzy language term set of the expert $e^{k}$ for the object $a_{i}(i=$ $1, \ldots, M)$ on the attribute $f_{j}(j=1, \ldots, N)$ is $H_{i j, S}^{k}$ and $H_{i j, v}^{k}$ represents the number of times the fuzzy language term $s_{v}(v=-\tau, \ldots, 0, \ldots, 1)$ which appears in $H_{i j, S}^{k}$; if $s_{v} \in H_{i j, S}^{k}$, $N_{i j, v}^{k}=1$, otherwise $N_{i j, v}^{k}=0$. Then, the information value of the expert $e^{k}$ for the object $a_{i}$ in the attribute $f_{j}$ can be expressed as

$$
\rho_{i j}^{k}=\sum_{v=-\tau}^{\tau} \frac{N_{i j, v}^{k}}{\sum_{v=-\tau}^{\tau} N_{i j, v}^{k}} I\left(s_{v}\right),
$$

where $I\left(s_{v}\right)$ denotes the subscript value [13] of the language term $s_{v}$. The information value matrix of the expert $e^{k}$ for the object set $A=\left\{a_{i} \mid i=1, \ldots, M\right\}$ can be represented as $R^{k}=\left(\rho_{i j}^{k}\right)_{M \times N}$.

The information value matrices of all experts are combined to form a new information value matrix:

$$
R=\left[\begin{array}{c}
R^{1} \\
R^{2} \\
\vdots \\
R^{K}
\end{array}\right]=\left(r_{i^{\prime} j^{\prime}}\right)_{(M \cdot K) \times N^{*}}
$$

Among them, $i^{\prime}=1,2, \ldots, M \cdot K, j^{\prime}=1,2, \ldots, N$.

Based on the information value matrix $R$, the calculation process of entropy weight $w_{j}$ of attribute $f_{j}$ in the expert evaluation process is as follows:

Step 1 (standardization of information matrix): for the information matrix $R=\left(r_{i^{\prime} j^{\prime}}\right)_{(M \cdot K) \times N}$, the normalized information value is denoted as $\bar{r}_{i^{\prime} j^{\prime}}$, and the normalized formula is denoted as 


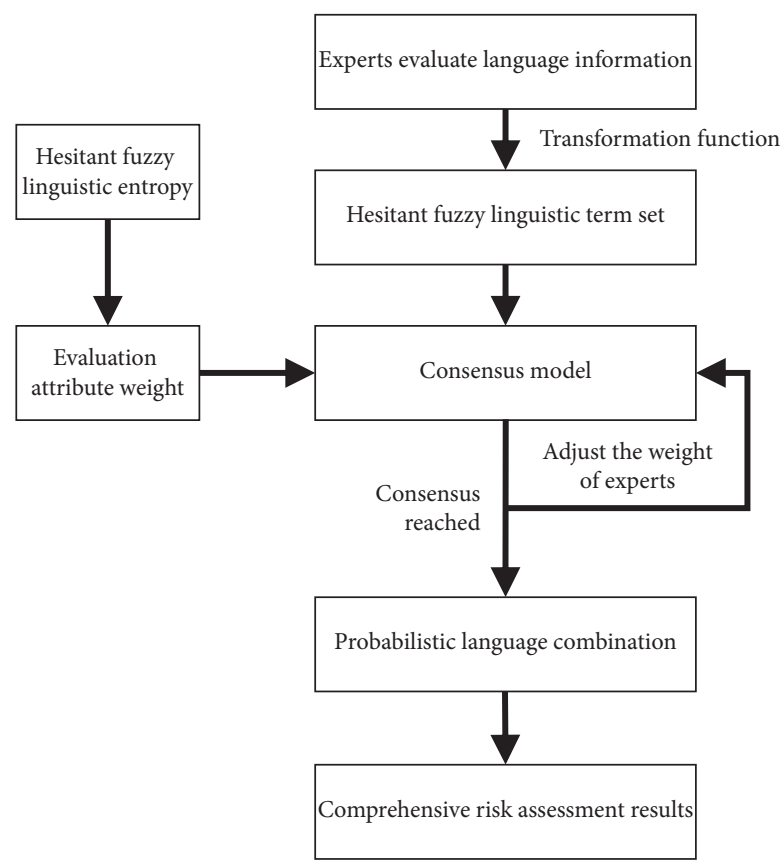

FIgURE 2: Comprehensive evaluation process of the talent growth factor index.

$$
\bar{r}_{i^{\prime} j^{\prime}}=\frac{\max _{i}\left\{\bar{r}_{i^{\prime} j^{\prime}}\right\}-\bar{r}_{i^{\prime} j^{\prime}}}{\max _{i}\left\{\bar{r}_{i^{\prime} j^{\prime}}\right\}-\min _{i}\left\{\bar{r}_{i^{\prime} j^{\prime}}\right\}} .
$$

Step 2: calculate the entropy of the attribute $f_{j}[14]$ :

$$
e_{j}=-\frac{1}{\ln (M \cdot K)} \sum_{i=1}^{M \cdot K} p_{i j} \ln \left(p_{i j}\right) \text {. }
$$

Among them, $p_{i j}=\left(\bar{r}_{i^{\prime} j^{\prime}} / \sum_{i=1}^{M \cdot K} \bar{r}_{i^{\prime} j^{\prime}}\right)$.

Step 3: calculate the weight value of each attribute:

$$
w_{j}=\frac{1-e_{j}}{\sum_{j=1}^{N}\left(1-e_{j}\right)} .
$$

\subsection{Expert Weight Adaptive Consensus Model.} Multiattribute group decision-making is a process involving multiple people and considering multiple attributes of the research and the evaluation object. It is widely applied in management practice, and the evaluation opinions of expert groups are unified by a consensus model that integrates group opinions and obtains the final decisions. In this paper, we proposed a new adaptive consensus model to calculate the cumulative consensus contribution of all experts. Besides, our model could impose nonconsensus punishment on the weight of less cooperative experts without asking them to alter their personal views, allowing adaptive consensus within the expert groups.

The expert opinion $e^{k}$ on the object $a_{i}$ in attribute $f_{j}$ is weighed through the weighted average operator to get the weighted aggregate individual evaluation score $\xi_{i}^{k}(i=1$, $\ldots, M ; k=1, \ldots, K)$, where

$$
\xi_{i}^{k}=\frac{1}{\tau} \sum_{j=1}^{N} w_{j} \rho_{i j}^{k}
$$

The group evaluation score value $\xi_{i}(i=1, \ldots, M)$ of the expert group with respect to the object $a_{i}$ can be obtained by the weighted average operator, where

$$
\xi_{i}=\sum_{k=1}^{K} \xi_{i}^{k} \lambda^{k}
$$

The consensus level of all experts in the expert group except the expert $e^{l}$ on the object $a_{i}$ can be calculated by equations (6) and (7), that is,

$$
\mathrm{CL}_{i}^{l}=\frac{\sum_{k \in\{(1, \cdots, K) / l\}}\left(1-\left|\xi_{i}^{k}-\xi_{i}\right|\right)}{K-1} .
$$

The consensus level of all experts on object $a_{i}$ is

$$
\mathrm{CL}_{i}=\frac{\sum_{k=1}^{K}\left(1-\left|\xi_{i}^{k}-\xi_{i}\right|\right)}{K} .
$$

For the object $A=\left\{a_{1}, \ldots, a_{M}\right\}$ with respect to the attribute set $F=\left\{f_{1}, \ldots, f_{N}\right\}$, the cumulative consensus contribution of the experts $e^{l}$ to the expert group is

$$
\mathrm{CD}^{l}=\sum_{i=1}^{M}\left(\mathrm{CL}_{i}-\mathrm{CL}_{i}^{l}\right) \text {. }
$$

Among them, $\mathrm{CD}^{l}$ is the contribution degree of expert $e^{l}$ to the group consensus. If $\mathrm{CD}^{l}>0$, expert $e^{l}$ would play a positive role in the group consensus process, and vice versa $[19,21]$.

The overall consensus of the expert group is 


$$
C=\frac{1}{M} \sum_{i=1}^{M} \mathrm{CL}_{i}=\frac{1}{M} \sum_{i=1}^{M} \sum_{k=1}^{K}\left(1-\left|\xi_{i}^{k}-\xi_{i}\right|\right) \lambda^{k}
$$

where $C$ is the overall consensus level of the group and greater $C$ means higher consensus of the expert group. Generally speaking, when establishing a consensus model, experts are required to preset a global threshold of consensus degree $\bar{C}$ according to the practical situation. If $C$ is smaller than $\bar{C}$, the model will calculate the cumulative consensus contribution of each expert and adaptively correct the weights of experts according to their contributions by the following correction method.

If $\lambda_{t}^{l}$ is the weight of expert $e^{l}$ after the $t$ th consensus adjustment and the cumulative consensus contribution of $e^{l}$ is $\mathrm{CD}_{t}^{l}$, the result of the $(t+1)$ th weight adjustment for $e^{l}$ would be

$$
\lambda_{t+1}^{l}=\frac{\mu_{t+1}^{l}}{\sum_{l=1}^{K} \mu_{t+1}^{l}}
$$

where $\mu_{t+1}^{l}=\lambda_{t}^{l}\left(1+\mathrm{CD}_{t}^{l}\right)^{\delta}, l=1,2, \ldots, K$. The convergence speed of the model can be adjusted by changing the value of $\delta$. Greater $\delta$ suggests faster convergence of the global consensus degree to the threshold. Generally speaking, when $t=0$, the initial weight $\lambda_{t}^{l}=(1 / K)$ can be given directly to all experts.

The implementation procedure of the expert weight adaptive consensus model based on the cumulative consensus contribution is as follows:

Step 1: according to calculation method in Section 3.2 , obtain the evaluation information value matrix $R^{k}=\left(\rho_{i j}^{k}\right)_{M \times N}(i \quad=1, \ldots, M ; j=1, \ldots, N ; k=1$, $\ldots, K)$ of all experts, the evaluation attribute weight $w_{j}^{k}$, and set the global consensus threshold $\bar{C}$ and the adjustment parameter $\delta$.

Step 2: Let $\mathrm{t}=0, \lambda_{0}^{l}=(1 / K), l=1,2, \ldots, K$.

Step 3: calculate the cumulative consensus contribution $\mathrm{CD}^{l}$ of expert $e^{l}$ to expert group according to formulas (6)-(10), calculate the global consensus degree $C$ of expert group according to formula (11), and output the expert consensus weight $\lambda^{l}:=\lambda_{t}^{l},(l=1,2, \ldots, K)$ if $C \geq \bar{C}$. Otherwise, turn to Step 4 .

Step 4: adjust the weight of each expert according to formula (12), and let $t:=t+1$; then, turn to Step 3 .

3.4. Integration of Expert Decision Information. To aggregate hesitation fuzzy language terms, a discrete hesitation fuzzy language is usually extended to a continuous language term set, making expert information in information aggregation more uncertain and leading to the loss of expert decision-making information. In order to minimize the information loss during aggregation, a probabilistic language transformation method is used to aggregate expert decision information.

A probability language combination can be written as $[13,14] P_{H_{s}}=\left\{\left(s_{t}, p_{t}\right) \mid t=-\tau, \ldots, 0, \ldots, \tau\right\}$, where $p_{t}$ is the probability of language term $s_{t}$. If the total number of times that expert $e^{l}$ thinks that attribute $f_{j}$ of decision object $a_{i}$ belongs to $s_{t}$ is $N_{i j, t}^{l}$, then $N_{i j, t}^{l}=\left\{\right.$ If $s_{t} \in H_{i j, S}^{l}, N_{i j, t}^{l}$
$=1$; Otherwise $\left.N_{i j, t}^{l}=0\right\}$, and the decision information of $e^{l}$ can be converted into a probabilistic language combination:

$$
P_{H_{S}}^{l}=\left\{\left(s_{t}, p_{i, t}^{l}\right) \mid s_{t} \in S ; i=1, \ldots, M ; t=-\tau, \ldots, \tau\right\} .
$$

Then, $p_{i, t}^{l}=\left(\sum_{j=1}^{N} w_{j} N_{i j, t}^{l} / \sum_{t=-\tau}^{\tau} \sum_{j=1}^{N} w_{j} N_{i j, t}^{l}\right)$.

By continuously integrating expert decision information, the probability language combination of each decision object can be obtained as

$$
P_{H_{s}}=\left\{\left(s_{t}, p_{i, t}\right) \mid s_{t} \in S ; i=1, \ldots, M ; t=-\tau, \ldots, \tau\right\} .
$$

Then, $p_{i, t}=\sum_{l=1}^{K} \lambda^{l} p_{i, t}^{l}$.

The expected value of the probability language combination of each decision object is calculated, and different decision objects can be compared in terms of their expected values:

$$
E_{i}=\sum_{t=-\tau}^{\tau} I\left(s_{t}\right) p_{i, t} .
$$

For decision objects $a_{i}, a_{j}(i, j=1, \ldots, M)$, if $E_{i}>E_{j}$, the ranking result is $a_{i}>a_{j}$. If $E_{i}<E_{j}$, the ranking result becomes $a_{i} \prec a_{j}$. If $E_{i}=E_{j}$, both the sum of squares of the average deviation and the average difference of the probability language combination of each decision object are calculated to determine the rankings, and the calculation equations are

$$
S_{i}^{2}=\frac{1}{2 \tau+1} \sum_{t=-\tau}^{\tau}\left(s_{t} p_{i, t}-E_{i}\right)^{2} .
$$

If $S_{i}^{2}>S_{j}^{2}$, the ranking result is $a_{i}<a_{j}$. If $S_{i}^{2}<S_{j}^{2}$, the ranking result is $a_{i}>a_{j}$. If $S_{i}^{2}=S_{j}^{2}$, it is considered $a_{i} \Leftrightarrow a_{j}$.

\section{Case Analysis}

In order to enable human capital as an advantage to promote global economic growth instead of labor, the comprehensive improvement of population quality has become one of the key directions in China. Particularly, an MMESE talent growth factor index system that integrates the era background is necessary for the comprehensive evaluation of talent growth. However, it is difficult for the talent growth factor index system to collect accurate numerical information of all the indicators, and the fuzziness of the index system also requires experts to make comprehensive evaluations based on their experience and knowledge.

4.1. Case Selection. In this paper, the hesitation fuzzy language consensus evaluation model was used to make comprehensive evaluations and comparisons between the MMESE talent growth factors' index system with other systems in previous studies (Table 2). Specifically, Case 3 is the MMSES talent growth factor index system proposed in this paper.

\subsection{Selection of Comprehensive Evaluation Factors and} Expert Evaluation Information. An index system is designed based on the accuracy of index selection, the difficulty of data acquisition, and the conceptual model and rationality of the indices. All these factors suggest the accuracy and scientificity of the model. The key indices for talent growth factor model 
TABLE 2: Case comparisons of talent growth factor index systems.

\begin{tabular}{|c|c|c|c|}
\hline $\begin{array}{l}\text { Serial } \\
\text { number }\end{array}$ & Article title & Author & Index selection \\
\hline Case 1 & $\begin{array}{l}\text { Research on the optimization model of the factors } \\
\text { influencing the growth of innovative talents }\end{array}$ & $\begin{array}{c}\text { B. } \\
\text { Wang }\end{array}$ & $\begin{array}{l}\text { Family upbringing style; family member relationship; } \\
\text { family cultural atmosphere; school psychological } \\
\text { environment; school cultural environment; school } \\
\text { curriculum system; the environment of communication } \\
\text { between teachers and students; the environment of policies } \\
\text { and regulations; innovative cultural atmosphere; research } \\
\text { and development investment; personal innovation } \\
\text { consciousness; personal innovation spirit; personal } \\
\text { innovative personality }\end{array}$ \\
\hline Case 2 & $\begin{array}{l}\text { Analysis on influencing factors of growth of young } \\
\text { scientific and technological talents in petroleum and } \\
\text { petrochemical industry }\end{array}$ & H. Feng & $\begin{array}{c}\text { Internal factors (quality: values, dedication, and } \\
\text { professionalism) } \\
\text { Professional knowledge, physical and mental health, and } \\
\text { teamwork } \\
\text { Character; ability: learning ability, thinking ability, } \\
\text { innovation ability, communication ability, and expression } \\
\text { ability); external factors (social environment, scientific and } \\
\text { technological practice group): environment, leadership, } \\
\text { and opportunity }\end{array}$ \\
\hline
\end{tabular}

evaluations should be selected based on the actual situation. Subsequently, the indicative effect of each index on the whole model should be analyzed, thereby establishing a reasonable index system. Particularly, pertinence, systematicness, practicality, foresight, dynamics, and completeness were selected as the evaluation indices in this study.

Three kinds of talent growth factor index systems' cases were selected for comprehensive evaluation. In other words, case 1 [22] $\left(a_{1}\right)$, case 2 [23] $\left(a_{2}\right)$, and case $3\left(a_{3}\right)$ were taken as the research objects, and the comprehensive evaluation opinions from five experts in talent education were obtained by questionnaires. The hesitation fuzzy language set was defined as $S=\left\{s_{-3}\right.$ : extremely low, $s_{-2}$ : low, $s_{-1}$ : slightly low, $s_{0}$ : general, $s_{1}$ : slightly high, $s_{2}$ : high, $s_{3}$ : extremely high\}; pertinence $\left(f_{1}\right)$, systematicness $\left(f_{2}\right)$, practicality $\left(f_{3}\right)$, prospective $\left(f_{4}\right)$, dynamic $\left(f_{5}\right)$, and completeness $\left(f_{6}\right)$ of the three talent growth factor index systems were evaluated by the experts. Whith text-free grammar and transformation function, the experts' evaluation languages were transformed into hesitation fuzzy language terms, and the transformation results are shown in Table 3.

\subsection{Comprehensive Evaluation of the Talent Growth Factor} Index System. According to formula (1), the evaluation information value matrix in Table 1 is counted, and the information value matrix is standardized, and the entropy value of the attribute $F=\left\{f_{1}, f_{2}, f_{3}, f_{4}, f_{5}, f_{6}\right\}$ is calculated as follows:

$$
\begin{aligned}
& e_{1}=0.9231, \\
& e_{2}=0.9158, \\
& e_{3}=0.8946, \\
& e_{4}=0.8871, \\
& e_{5}=0.8703, \\
& e_{6}=0.8330
\end{aligned}
$$

The weight of the attribute $F=\left\{f_{1}, f_{2}, f_{3}, f_{4}, f_{5}, f_{6}\right\}$ is further calculated:

$$
\begin{aligned}
& w_{1}=0.1137, \\
& w_{2}=0.1246, \\
& w_{3}=0.1559, \\
& w_{4}=0.1670, \\
& w_{5}=0.1918, \\
& w_{6}=0.2470 .
\end{aligned}
$$

Let $t=0$, the initial weight of experts $\lambda_{k}=0.2(k=1,2, \ldots, 10)$, the threshold value of global consensus degree, $\bar{C}=0.95$, and the adjustment parameter $\delta=0.6$, and the cumulative consensus contribution degree of five experts is obtained as follows: $\mathrm{CD}_{1}=0.0005$, $\mathrm{CD}_{2}=-0.0104, \quad \mathrm{CD}_{3}=0.0168, \quad \mathrm{CD}_{4}=0.0269, \quad$ and $\mathrm{CD}_{5}=-0.0003$. The overall consensus degree of expert groups is $C_{0}=08917$. Since $C_{0}<\bar{C}$, we adjust the expert 
TABLE 3: Evaluation information of the expert hesitant fuzzy language term set of the talent growth factor index system.

\begin{tabular}{|c|c|c|c|c|c|c|c|c|c|}
\hline & \multicolumn{3}{|c|}{$a_{1}$} & \multicolumn{3}{|c|}{$a_{2}$} & \multicolumn{3}{|c|}{$a_{3}$} \\
\hline & $f_{1}$ & $f_{2}$ & $f_{3}$ & $f_{1}$ & $f_{2}$ & $f_{3}$ & $f_{1}$ & $f_{2}$ & $f_{3}$ \\
\hline$e_{1}$ & $\left\{s_{1}\right\}$ & $\left\{s_{-2}\right\}$ & $\left\{s_{1}\right\}$ & $\left\{s_{-1}\right\}$ & $\left\{s_{-3}\right\}$ & $\left\{s_{-1}\right\}$ & $\left\{s_{2}, s_{3}\right\}$ & $\left\{s_{3}\right\}$ & $\left\{s_{2}\right\}$ \\
\hline$e_{2}$ & $\left\{s_{-2}, s_{-1}\right\}$ & $\left\{s_{-3}, s_{-2}\right\}$ & $\left\{s_{2}\right\}$ & $\left\{s_{-2}, s_{-1}\right\}$ & $\left\{s_{2}\right\}$ & $\left\{s_{-1}\right\}$ & $\left\{s_{2}\right\}$ & $\left\{s_{2}\right\}$ & $\left\{s_{1}\right\}$ \\
\hline$e_{3}$ & $\left\{s_{-2}, s_{-1}\right\}$ & $\left\{s_{-2}, s_{-1}\right\}$ & $\left\{s_{3}\right\}$ & $\left\{s_{-1}, s_{0}\right\}$ & $\left\{s_{1}, s_{2}\right\}$ & $\left\{s_{-1}, s_{0}\right\}$ & $\left\{s_{-1}\right\}$ & $\left\{s_{0}\right\}$ & $\left\{s_{2}, s_{3}\right\}$ \\
\hline$e_{4}$ & $\left\{s_{-1}\right\}$ & $\left\{s_{-2}\right\}$ & $\left\{s_{1}, s_{2}\right\}$ & $\left\{s_{-1}\right\}$ & $\left\{s_{2}\right\}$ & $\left\{s_{-1}\right\}$ & $\left\{s_{2}\right\}$ & $\left\{s_{1}, s_{2}\right\}$ & $\left\{s_{1}\right\}$ \\
\hline$u_{5}$ & $\left\{s_{3}\right\}$ & $\frac{\left\{s_{-2}\right\}}{a_{1}}$ & $\left\{s_{1}\right\}$ & $\left\{S_{-3}\right\}$ & $\frac{\left\{s_{1}, s_{2}\right\}}{a_{2}}$ & $\left\{S_{-1}\right\}$ & $\left\{s_{3}\right\}$ & $\frac{\left\{s_{1}\right\}}{a_{3}}$ & $\left\{s_{3}\right\}$ \\
\hline$e_{1}$ & $\begin{array}{c}f_{4} \\
\left\{s_{1}\right\}\end{array}$ & $\begin{array}{c}f_{5} \\
\left\{s_{2}\right\}\end{array}$ & $\begin{array}{c}f_{6} \\
\left\{s_{-2}\right\}\end{array}$ & $\begin{array}{c}f_{4} \\
\left\{s_{1}\right\}\end{array}$ & & $\begin{array}{c}f_{6} \\
\left\{s_{2}\right\}\end{array}$ & $\begin{array}{c}f_{4} \\
\left\{s_{3}\right\}\end{array}$ & $\begin{array}{c}f_{5} \\
\left\{s_{3}\right\}\end{array}$ & $\begin{array}{c}f_{6} \\
\left\{s_{1}\right\}\end{array}$ \\
\hline$e_{2}$ & $\left\{s_{0}\right\}$ & $\left\{s_{1}, s_{2}\right\}$ & $\left\{s_{-1}\right\}$ & $\left\{s_{-2}, s_{-1}\right\}$ & $\left\{s_{-1}\right\}$ & $\left\{s_{2}\right\}$ & $\left\{s_{2}\right\}$ & $\left\{s_{-1}\right\}$ & $\left\{s_{2}\right\}$ \\
\hline$e_{3}$ & $\left\{s_{-2}\right\}$ & $\left\{s_{1}\right\}$ & $\left\{s_{0}, s_{-1}\right\}$ & $\left\{s_{1}\right\}$ & $\left\{s_{-3}\right\}$ & $\left\{s_{1}, s_{-1}\right\}$ & $\left\{s_{2}, s_{3}\right\}$ & $\left\{s_{2}, s_{3}\right\}$ & $\left\{s_{-1}, s_{0}\right.$ \\
\hline$e_{4}$ & $\left\{s_{1}\right\}$ & $\left\{s_{1}, s_{2}\right\}$ & $\left\{s_{-2}, s_{-1}\right\}$ & $\left\{s_{-1}, s_{0}, s_{1}\right\}$ & $\left\{s_{-2}, s_{-1}\right\}$ & $\left\{s_{1}, s_{2}\right\}$ & $\left\{s_{2}\right\}$ & $\left\{s_{2}\right\}$ & $\left\{s_{2}\right\}$ \\
\hline$\underline{e_{5}}$ & $\left\{s_{2}\right\}$ & $\left\{s_{3}\right\}$ & $\left\{s_{-1}\right\}$ & $\left\{s_{1}\right\}$ & $\left\{s_{-1}\right\}$ & $\left\{s_{1}\right\}$ & $\left\{s_{3}\right\}$ & $\left\{s_{2}\right\}$ & , \\
\hline
\end{tabular}

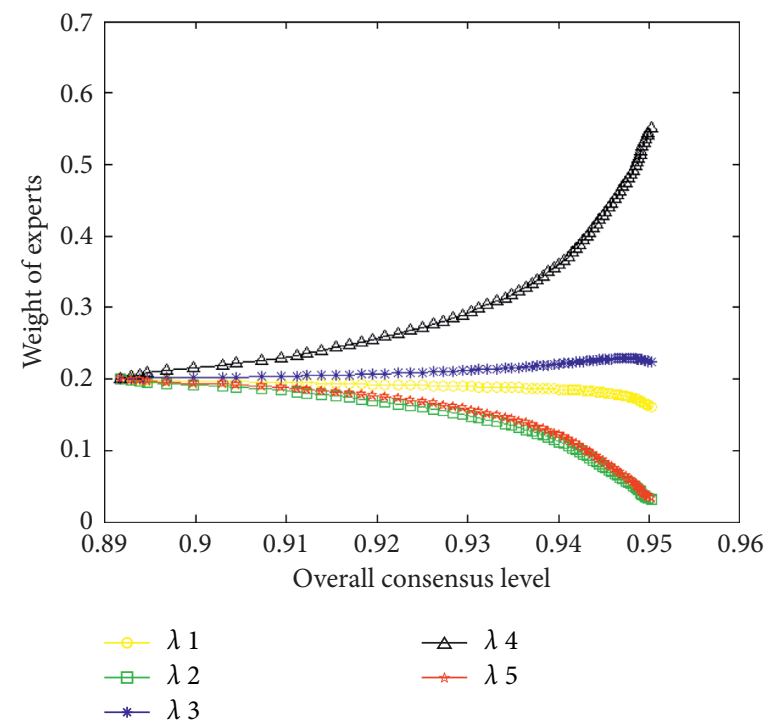

Figure 3: The change of expert adaptive weight and global consensus degree.

weight $\lambda_{k}$ according to formula (12) and repeat the above steps. After 73 rounds of consensus iteration, the global consensus degree $C=0.9503$ is obtained. At this time, $C>\bar{C}$; the expert group reaches a consensus. The expert consensus weight is $\lambda_{1}=0.1612, \lambda_{2}=0.0316, \lambda_{3}=0.2242, \lambda_{4}=0.5502$, and $\lambda_{5}=0.0328$. The change of the group consensus level with the update of expert weight is shown in Figure 3.

According to formulas (13) and (14), the expert evaluation information is converted into a probabilistic language combination:

$$
\begin{aligned}
& P_{H_{s}, 1}=\left\{\left(s_{-3}, 0.03\right),\left(s_{-2}, 0.24\right),\left(s_{-1}, 0.20\right),\left(s_{0}, 0.04\right),\left(s_{1}, 0.27\right),\left(s_{2}, 0.16\right),\left(s_{3}, 0.06\right)\right\}, \\
& P_{H_{s}, 2}=\left\{\left(s_{-3}, 0.07\right),\left(s_{-2}, 0.07\right),\left(s_{-1}, 0.40\right),\left(s_{0}, 0.04\right),\left(s_{1}, 0.23\right),\left(s_{2}, 0.19\right),\left(s_{3}, 0\right)\right\}, \\
& P_{H_{s}, 3}=\left\{\left(s_{-3}, 0\right),\left(s_{-2}, 0\right),\left(s_{-1}, 0.06\right),\left(s_{0}, 0.03\right),\left(s_{1}, 0.22\right),\left(s_{2}, 0.46\right),\left(s_{3}, 0.23\right)\right\} .
\end{aligned}
$$

According to formula (15), the expected value of the three cities is calculated, and the final ranking result is $a_{2}>a_{3}>a_{1}$, that is, the ranking of the three talent growth factor index systems.

\section{Conclusion}

The talent growth factor index system is the primary problem of research in talent training, talent pool building, 
and talent policy formulation. An accurate evaluation of the talent growth factor index system could act as strategic support for decision-making. This paper intuitively expresses the opinions of experts on talent evaluation by using language information and determines the attribute weight and expert weight in the process of talent evaluation through hesitation fuzzy language entropy calculation and expert weight adaptive consensus model. The model avoids the influence of subjective factors given artificially. It provides an effective method to solve the attribute uncertainty information processing in the process of talent evaluation. At the same time, this method can also be used in different application scenarios, which are helpful to improve the comprehensive evaluation system. Finally, case analysis conclusions with the MMESE talent growth factor index system proposed in this paper are consistent with the expectations. Therefore, it is an effective solution to process information with uncertain attributes during comprehensive evaluations, which is conducive to in-depth research studies on talent training and talent pool construction.

\section{Data Availability}

All data and models generated or used during the study are available within the article.

\section{Conflicts of Interest}

The authors declare no conflicts of interest.

\section{Authors' Contributions}

X.J., L.W., and H.X. conceptualized the study; X.J.and L.W. developed the methodology; X.J. helped with software; X.J. validated the study; X.J.and L.W. carried out formal analysis; X.J. investigated the study; X.J. collected the resources; X.J. and L.W. curated the data; X.J. wrote and prepared the original draft; X.J. visualized the study; H.X. supervised the study; H.X. administrated the project; H.X. carried out funding acquisition. All authors have read and agreed to the published version of the manuscript.

\section{Acknowledgments}

This research was funded by the "Hsue-Shen Tsien's life and thought research" organization of Shanghai Jiao Tong University in 2019 and National Natural Science Foundation of China (U1501253) (research on the formation factors and successful models of strategic scientists).

\section{References}

[1] Y. Qiu, "Construction of the Evaluation System of International Applied Innovative Talents," Journal of Ningbo University (Humanities Edition), vol. 6, pp. 76-79, 2007.

[2] Q. H. Tian, X. Han, and Y. L. Lei, "Research status and future research direction of innovative talents cultivation theory," Road to Success, vol. 25, pp. 1-3, 2016.

[3] Y. Liu, Research Report on Cultivation and Growth of Innovative Talents, Science Press, Beijing, China, 2013.
[4] A. W. Labib, G. B. Williams, and R. F. O’Connor, "An intelligent maintenance model (system): an application of the analytic hierarchy process and a fuzzy logic rule-based controller," Journal of the Operational Research Society, vol. 49, no. 7, pp. 745-757, 1998.

[5] S. Petrovic-Lazarevic, "Personnel selection fuzzy model," International Transactions in Operational Research, vol. 8, no. 1, pp. 89-105, 2001.

[6] R. M. Rodríguez, L. Martínez, and F. Herrera, "Hesitant fuzzy linguistic term sets," IEEE Transactions on Fuzzy Systems, vol. 20, pp. 109-119, 2012.

[7] C. Wei, Z. Ren, and R. M. Rodríguez, "A hesitant fuzzy linguistic TODIM method based on a score function," International Journal of Computational Intelligence Systems, vol. 8, no. 4, pp. 701-712, 2015.

[8] C. P. Wei and J. Ma, "Consensus model for hesitant fuzzy linguistic group decision making," Control and Decision, vol. 33, no. 2, pp. 275-281, 2018.

[9] A. Muhanmmad, L. Anam, and K. Cengiz, "Hesitant Pythagorean fuzzy ELECTRE-II method for multi-criteria decision-making problems," Applied Soft Computing, vol. 108, pp. 107-479, 2021.

[10] B. G. Wang, W. Wang, W. G. Huang, H. S. Chen, X. Q. Wang, and Y. J. Xu, "Application of H. S. Tsien's systems science in man-machine-environment system engineering," Journal of North China Institute of Science and Technology, vol. 11, no. 8, pp. 1-18, 2014.

[11] S. Z. Long, "The role and status of man-machine-environment system engineers in contemporary society," Research Progress of Man-Machine-Environment System Engineering, vol. 7, p. 5, 2005.

[12] X. Chen and S. Z. Long, “"Historical documents: introduction to man-machine-environment systems engineering," China society of Systems Engineering, vol. 10, p. 5, 2001.

[13] Y. Dong and Q. Wu, "Analysis of the current situation and countermeasures of the construction of young talents in the capital," in Proceedings of the Beijing Federation of Social Sciences Conference, Beijing, China, April 2012.

[14] G. B. Fan, "On the quality characteristics of young talents," Science and Technology Information, vol. 1, p. 212, 2010.

[15] G. Z. Fang and X. J. Wang, "Analysis of quality model of innovative talents based on personality traits," Journal of Northeastern University, vol. 3, pp. 106-108, 2007.

[16] Y. M. Feng, Research on Innovative Talents, pp. 101-102, Southwest Jiaotong University Press, Chengdu, China, 2006.

[17] V. Torra, "Hesitant fuzzy sets," International Journal of Intelligent Systems, vol. 25, no. 6, pp. 529-539, 2010.

[18] R. M. Rodriguez, L. Martinez, and F. Herrera, "Hesitant fuzzy linguistic term sets for decision making," IEEE Transactions on Fuzzy Systems, vol. 20, no. 1, pp. 109-119, 2012.

[19] H. Liao and Z. Xu, "Approaches to manage hesitant fuzzy linguistic information based on the cosine distance and similarity measures for HFLTSs and their application in qualitative decision making," Expert Systems with Applications, vol. 42, no. 12, pp. 5328-5336, 2015.

[20] S. T. Zhang, J. J. Zhu, X. D. Liu, and Z. P. Chang, "Uncertain linguistic consensus decision-making method based on cumulative consensus contribution," Operations Research and Management, vol. 27, no. 7, pp. 93-101, 2018.

[21] Z. Z. Ma, J. J. Zhu, S. T. Zhang, H. H. Wang, and X. D. Liu, "Large-scale group classification aggregation model for hesitant fuzzy linguistic information," Control and Decision, vol. 34, no. 1, pp. 167-179, 2019. 
[22] B. Wang, "Research on the optimization model of influencing factors on the growth of innovative talents," Research on Science and Technology Management, vol. 33, no. 15, pp. 156-160, 2013.

[23] H. Feng, "Analysis of influencing factors on the growth of young scientific and technological talents in petroleum and petrochemical industry," Journal of Institute of Petrochemical Management Cadres, vol. 14, no. 1, pp. 80-84, 2012. 